\title{
Journal of International Technology and Information Management
}

2014

\section{Assessing Web Site Usability in Retail Electronic Commerce}

Charles E. Downing

Northern Illinois University

Chang Liu

Northern Illinois University

Follow this and additional works at: https://scholarworks.lib.csusb.edu/jitim

Part of the Management Information Systems Commons

\section{Recommended Citation}

Downing, Charles E. and Liu, Chang (2014) "Assessing Web Site Usability in Retail Electronic Commerce," Journal of International Technology and Information Management. Vol. 23: Iss. 1, Article 3.

DOI: https://doi.org/10.58729/1941-6679.1063

Available at: https://scholarworks.lib.csusb.edu/jitim/vol23/iss1/3

This Article is brought to you for free and open access by CSUSB ScholarWorks. It has been accepted for inclusion in Journal of International Technology and Information Management by an authorized editor of CSUSB ScholarWorks. For more information, please contact scholarworks@csusb.edu. 


\title{
Assessing Web Site Usability in Retail Electronic Commerce
}

\author{
Charles E. Downing \\ Chang Liu \\ Operations Management and Information Systems Department \\ Northern Illinois University \\ USA
}

\begin{abstract}
In the increasingly competitive environment of electronic commerce, companies are paying careful attention to Web site design and function to attract and retain both traffic and customers. One key factor that has been shown to increase both is Web site usability. This paper presents and tests a Web site usability research framework derived from prior literature. Fourteen Fortune 500 retail Web sites are examined by 261 potential customers and rated on aspects of usability. Results show that Content and Ease of Use are not currently differentiating sites with regard to usability (these attributes are expected and required just to survive in electronic commerce), but Identity, Download Delay, Trust Assurance, Made-for-the-medium, Responsiveness and Emotion can all be differentiators for a site's usability.
\end{abstract}

\section{INTRODUCTION AND BACKGROUND}

Electronic commerce (EC) continues to explode. About $39 \%$ of the World's population (61\% in the Americas) was using the Internet in 2013 (International Telecommunications Unions, 2013), and this penetration is predicted to increase. And for many of these users, shopping online has become the normal way of doing business rather than an exception. eMarketer lists global EC sales at over \$1.2 Trillion in 2013, with strong growth forecasted (eMarketer, 2013). With so much economic activity happening online, companies need to ensure that their Web presence is accessible and acceptable to maintain future profitability.

As Downing and Liu (2009) discussed, usability is one prominent measure of accessibility and acceptability. Importantly, they demonstrated that usability correlates with web site usage. If customers find a site "usable" they are more likely to frequent the site. Nielsen (2000) showed that such increased traffic often translates into customers. Venkatesh and Agarwal (2006) confirmed that usability is a significant predictor of purchase behavior.

Retail companies need to be able to determine the usability of their site, and reliable measurement of usability is needed. Downing and Liu (2009, pg. 444) enumerated prior research on usability: "Eighmey and McCord (1998) derived seventeen factors tapping into different aspects of Web site usability that were subsequently reduced to nine groups including dimensions such as personal involvement, useful information, simplicity of organization, and desire for relationship. Agarwal and Venkatesh (2002) employed the Microsoft Usability Guidelines (MUG) to assess usability of multiple Web sites from four different industry sectors: airlines, online bookstores, automobile manufacturers, and car rental agencies. The MUG guidelines include five major categories that collectively tap into different aspects of Web site usability: content, ease of use, promotion, made-for-the medium, and emotion. Venkatesh and 
Ramesh (2006) concluded that the MUG-based model outperformed the widely employed Technology Acceptance Model (TAM) both in terms of richness and variance explained (about 70 percent compared to 50 percent)."

While the MUG-based usability model provided a solid foundation for guiding Web site design, some important factors derived from electronic commerce literature such as identity of a Web site (Nielsen, 2000), Web trust assurance (Everard \& Galletta, 2006), download delay (Palmer, 2002), and responsiveness (Palmer, 2002) were missing from the MUG related studies. The MUG guidelines need to be expanded to test the validity and applicability of the model. The authors of the validating MUG study themselves state "Future research should examine the possibility of adding or removing more categories and subcategories to the guidelines based on both theoretical and practical considerations" (Venkatesh \& Ramesh, 2006, pg. 201). Moreover, the weights which provide relative importance assigned to the five major categories in the MUG related studies were quite subjective and were determined by the sites' evaluators (Massey, Khatri, \& Montoya-Weiss, 2007). An objective and scientific method is needed to elicit usability category and subcategory weights and to access user preference with the selected business Web sites. Therefore, there exists a strong appeal to further explore usability in the context of electronic commerce to develop a comprehensive instrument to evaluate Web site usability. This study will examine all factors enumerated from the research above (the five MUG factors and the additional four factors mentioned specifically in the electronic commerce literature) and determine the contribution of each in assessing a web site's usability.

Therefore, the purpose of this research is expand on previous usability research by applying established factors, as well as identifying and adding factors, associated with Web site usability. The research will also present empirical results obtained from users of operating retail Web sites. The study should provide valuable information to guide business organizations looking to redesign their Web sites to obtain positive responses and increased use from their customers.

\section{RESEARCH FRAMEWORK AND HYPOTHESES}

Figure 1 presents the proposed research framework.

The following are brief descriptions for each construct presented in Figure 1:

\section{Identity}

Many Web sites were created with similar presence so that differentiation is not possible. In order to increase Web site traffic, the purpose of the site should be clearly stated. In addition, the site design should reflect uniqueness of the site and the characteristics that make the site unique in a world of Web sites (Nielsen, 2000). Thus, the following hypothesis is suggested in this study:

\section{$H_{1}$ : Identity of a Web site will have a significant positive effect on Web site usability.}




\section{Download Delay}

Download delay can be defined as the initial request for access to the page and then each subsequent request for changing pages with the site (Palmer, 2002). Electronic commerce literature suggests that the length of wait during a site visit is important, as users are unwilling to wait even a handful of seconds for a response (Moustakis, Tsironis, \& Litos, 2006). While such factors are of course related to a user's individual connection speed, the users in this study all had access to nearly identical connection speeds (in university laboratories), and therefore any difference in delay would be caused by the web site (and its underlying infrastructure) itself. This suggests the second hypothesis:

\section{$\mathrm{H}_{2}:$ A Web site exhibiting lower download delay will have a significant positive effect on Web site usability.}

\section{Content}

Content reflects quality, completeness, and reliability of information included in a Web site (Agarwal and Venkatesh, 2002). The MUG guidelines suggest multiple subcategories that, in fact, capture various aspects associated with content. These subcategories are: relevance, relating to the pertinence of the content to the core audience; media use, signifying the appropriate use of multimedia content; depth/breadth, examining the appropriate range and detail of topics; and current and timely information, capturing the extent to which a Web site's content is current. Therefore, the third hypothesis is proposed:

\section{$\mathrm{H}_{3}$ : A well designed Web site content will have a significant positive effect on Web site usability.}

\section{Ease of Use}

Ease of use ties to an individual's assessment of the mental effort involved in using a Web site. The construct of ease of use has been employed extensively in information systems research (Venkatesh, Morris, Davis, \& Davis, 2003) and has been shown to be an important predictor of technology acceptance outcomes. Well designed navigation and search options reflect the support provided to the user when moving in and around the site. This suggests the following hypothesis:

\section{$H_{4}:$ Perceived ease of use a Web site will have a significant positive effect on Web site usability.}

\section{Trust Assurance}

As organizations place greater emphasis on building long-term relationships with their customers, trust has assumed a central role. A successful relationship requires businesses to describe their information collection practices and policies on the Web site. Customers, in turn, must be willing to provide personal information to enable businesses to advance the customer relationships through improved offerings and targeted communications (Everard \& Galletta, 
2006). All business transactions require an element of trust, especially those conducted in the virtual environment. From this perspective, security and privacy protections are critical to trust assurance and lead to the following hypothesis:

\section{$H_{5}:$ Web site trust assurance will have a significant positive effect on the Web site usability.}

\section{Made-for-the-medium}

The ability to provide a personalized, customized interaction for the user allows Web site design that differentiates product and service offerings. In addition, higher Made-for-the-medium in a Web site will improve the site identity (Palmer and Griffith, 1998). Made-for-the-medium includes the ability to customize the site's look, feel, and content as well as provide interaction with the user. This suggests the Made-for-the-medium hypothesis:

\section{$H_{6}:$ Higher Made-for-the-medium in a Web site will have a significant positive effect on Web site usability.}

\section{Responsiveness}

In any business, customer service plays an important part in delivering service quality to the customer. Prior research suggests that feedback options and access to previously asked questions (FAQ) are important for the customer when engaging in online activities on the Web. This suggests the following hypothesis:

\section{$H_{7}:$ A more responsive Web will have a significant positive effect on Web site usability.}

\section{Promotion}

Promotion captures the advertising of a Web site on the Internet and other media. Promotion should communicate the primary features, goals, or themes of the site. It has to convey an appealing attitude to its target audience (Keeker, 2008). Many Web sites failed to use their promotional spots to let people know that they have time-sensitive events and constantly fresh content (Venkatesh \& Ramesh, 2006). This leads to the following hypothesis:

\section{$H_{8}:$ A well designed promotion will have a significant positive effect on Web site usability.}

\section{Emotion}

Information systems literature suggests that the likelihood of a repeat visit to a Web site is enhanced when the visitors find the visit enjoyable. A satisfied customer not only comes from an extrinsic reward of purchasing products or services but also from personal and emotional rewards from online activities which create a pleasurable experience for the user (Keeker 2008). This suggests the Emotion hypothesis: 


\section{H9: Emotion will have a significant positive effect on the Web site usability.}

Figure 1. Research Framework for Assessing Web Site Usability.

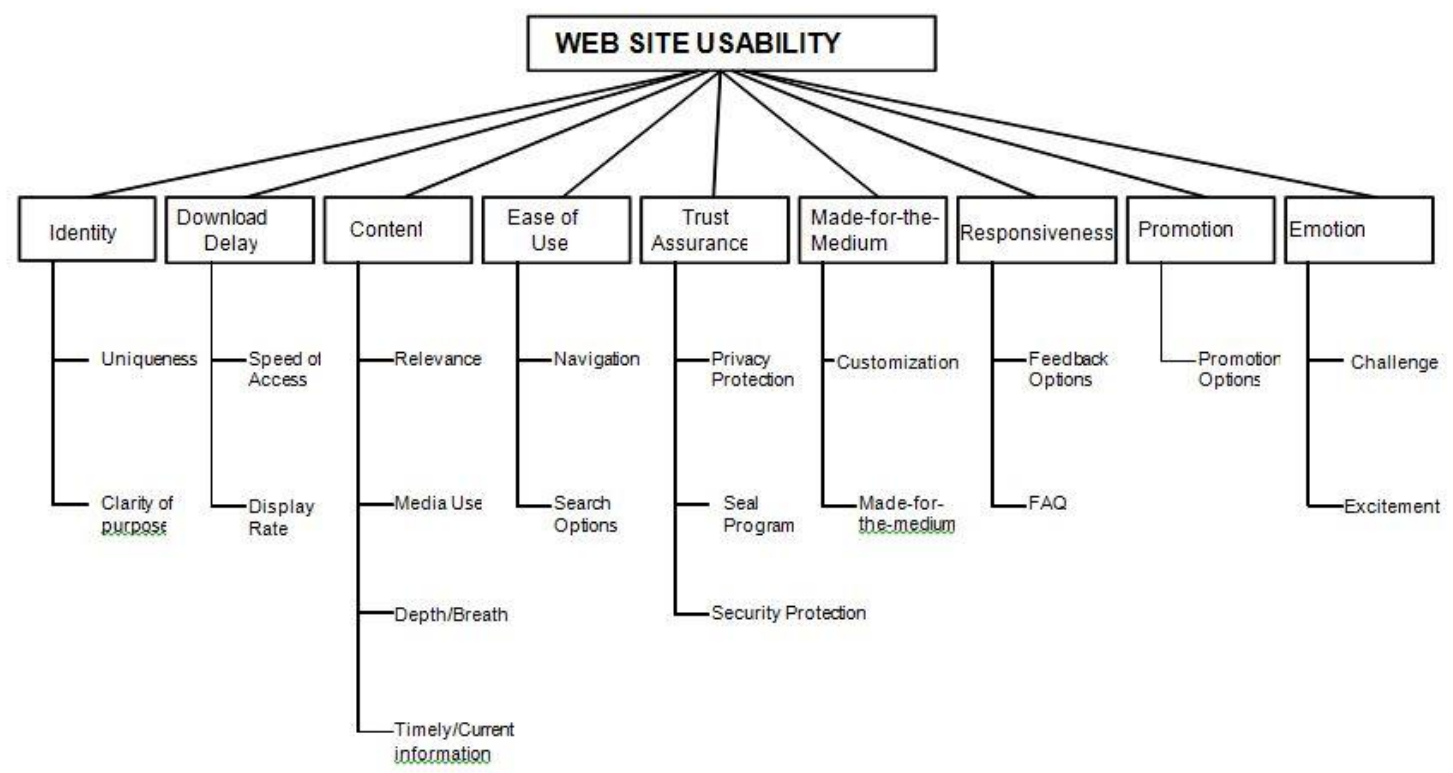

RESEARCH METHODOLOGY AND DATA COLLECTION

The study consisted of the review of commercial retail Web sites by students majoring in Business who will serve as customer surrogates to test the proposed research framework for Web site usability. Large business organizations are known to provide leadership in the use of information technology. Therefore, this research used fourteen different retail Web sites from the Fortune 500 ( $\underline{\text { www.fortune.com }}$ ) to study consumer-focused Web site usability. Table 1 lists the companies and associated Web sites used, as well as the number of survey respondents per Web site.

As shown in Table 1, each Web site was reviewed by at least 14 Business students. The students received a small amount of class participation extra credit to complete the survey. A short paragraph describing the Web site which each student visited was also required, in an attempt to verify that the respondent was going to the correct site and answering the questions carefully. Three hundred and twenty-five students were given the opportunity to participate in the study, and 264 took the opportunity, for a response rate of $81 \%$. Of the 264 responses, 3 were deemed unusable, leaving 261 total usable responses. All measures in the questionnaire were done on a seven-point Likert scale ranging from "completely disagree" to "completely agree". 
Table 1. Web Sites Visited and Number of Survey Responses per Site

Site Address
www.belk.com
www.bonton.com
www.dillards.com
www.dollargeneral.com
www.familydollar.com
www.fds.com
www.jcpenney.net
www.kohls.com
www.nordstrom.com
www.retailventuresinc.com
www.saksincorporated.com
www.searsholdings.com
www.target.com
www.walmart.com

\section{Company}

Belk

Bonton

Dillards

Dollar General

Family Dollar

FDS

JC Penny

Kohls

Nordstrom

Retail Ventures

Saks

Sears Holdings

Target

Wal-Mart

\section{$\underline{\text { Site Visitors }}$}

/ Survey

Respondents

16

20

18

14

19

22

18

21

21

19

18

17

18

20

261

The full survey instrument is included in the Appendix. Table 2 shows the mapping of the constructs from Figure 1 to the question numbers in the survey, as well as how many survey questions were used for each construct.

Table 2. Map of constructs with survey questions.

\begin{tabular}{|l|c|c|}
\hline Construct & $\begin{array}{c}\text { Total Number of } \\
\text { Survey Questions } \\
\text { for Construct }\end{array}$ & Question Numbers \\
\hline Identity & 2 & $1,2$. \\
\hline Download Delay & 2 & $3,4$. \\
\hline Content & 4 & $5,6,7,8$. \\
\hline Ease of Use & 4 & $9,10,11,12$. \\
\hline Trust Assurance & 5 & $13,14,15,16,25$. \\
\hline $\begin{array}{l}\text { Made-for-the- } \\
\text { Medium }\end{array}$ & 3 & $19,20,31$. \\
\hline Responsiveness & 3 & $21,22$. \\
\hline Promotion & 2 & $26,24.28,29,32$. \\
\hline Emotion & 5 & \\
\hline Web Site Usability & 2 & \\
\hline
\end{tabular}




\section{RESULTS}

We used the standard version of SPSS for Windows, Release 16.0 to perform all analyses. Reliability of constructs was assessed using Cronbach's Alpha for scales with three or more items and correlation analysis for scales with two items. Given that the constructs Content, Ease of Use, Trust Assurance, Made-for-the-medium, Responsiveness, and Web Site Usability all had more than two questions (items) for measurement, Cronbach's Alpha was used to check the reliability of each construct. The constructs Identity, Download Delay, Promotion, and Emotion each had two questions, and as such correlation analysis was used. Cronbach's Alpha results above .6 are considered to demonstrate reliability of a construct, as well as correlation significance at the .01 level (Hair, et al., 2005). Table 3 shows the results.

Table 3. Cronbach's Alpha or Correlation Significance for Each Construct.

\begin{tabular}{|l|c|c|c|}
\hline Construct & $\begin{array}{c}\text { Cronbach's } \\
\text { Alpha }\end{array}$ & $\begin{array}{c}\text { Correlation } \\
\text { Significance }\end{array}$ & $\begin{array}{c}\text { Construct } \\
\text { Reliable? }\end{array}$ \\
\hline Identity & & $\begin{array}{c}\text { Significant at the } \\
\text {.01 level }\end{array}$ & Yes \\
\hline $\begin{array}{l}\text { Download } \\
\text { Delay }\end{array}$ & $\begin{array}{c}\text { Significant at the } \\
.01 \text { level }\end{array}$ & Yes \\
\hline Content & .660 & & Yes \\
\hline Ease of Use & .706 & & Yes \\
\hline Trust Assurance & .855 & & Yes \\
\hline $\begin{array}{l}\text { Made-for-the- } \\
\text { medium }\end{array}$ & .755 & Yes \\
\hline Responsiveness & .628 & Significant at the & Yes level \\
\hline $\begin{array}{l}\text { Promotion } \\
\text { Site }\end{array}$ & .892 & $\begin{array}{c}\text { Significant at the } \\
.01 \text { level }\end{array}$ & Yes \\
\hline Emotion & & Yes \\
\hline $\begin{array}{l}\text { Web Usability } \\
\text { Ust }\end{array}$ & & Yes \\
\hline
\end{tabular}

Following the guidelines of Hair, et al. (2005), the multiple questions for each of the Cronbach's Alpha constructs, given their high results (all above .6), were averaged into one number to represent that construct in a multiple regression analysis. The high significance level (.01 level) of the correlated constructs also allows the averaging of the questions into one number to represent that construct in a multiple regression analysis (Hair, et al., 2005). Tables 4 and 5 show the results of the multiple regression model. 
Table 4. Multiple Regression Model Summary.

\begin{tabular}{|c|c|c|c|c|}
\hline Model & $\mathrm{R}$ & $\mathrm{R}$ Square & $\begin{array}{c}\text { Adjusted R } \\
\text { Square }\end{array}$ & $\begin{array}{c}\text { Std. Error of } \\
\text { the Estimate }\end{array}$ \\
\hline 1 & $.892^{\mathrm{a}}$ & .795 & .788 & .6601728 \\
\hline
\end{tabular}

a. Predictors: (Constant), Emotion, Delay, Promo, Identity, Easy, Trust, Content, Made-for-the-Medium, Responsive

Table 5. Coefficients of Multiple Regression Model ${ }^{\text {a. }}$

\begin{tabular}{|c|c|c|c|c|c|}
\hline \multirow{2}{*}{ Model } & \multicolumn{2}{|c|}{$\begin{array}{c}\text { Unstandardized } \\
\text { Coefficients }\end{array}$} & $\begin{array}{c}\text { Standardized } \\
\text { Coefficients }\end{array}$ & & \\
\cline { 2 - 4 } (Constant) & -.825 & .296 & & -2.785 & .006 \\
Identity & .152 & .044 & .125 & 3.419 & .001 \\
Delay & .130 & .049 & .090 & 2.643 & .009 \\
Content & -.089 & .065 & -.060 & -1.370 & .172 \\
Easy & .004 & .055 & .003 & .069 & .945 \\
Trust & .115 & .044 & .115 & 2.638 & .009 \\
Made-for & .422 & .055 & .389 & 7.645 & .000 \\
Responsive & .361 & .057 & .323 & 6.284 & .000 \\
Promo & -.030 & .034 & -.032 & -.880 & .380 \\
Emotion & .132 & .039 & .134 & 3.411 & .001 \\
\hline
\end{tabular}

a. Dependent Variable: Usability

\section{DISCUSSION AND CONCLUSIONS}

The .795 R-square in Table 4 indicates that approximately $80 \%$ of the variance in Usability is explained by the nine factors in the research model. The significance levels of the coefficients (Betas) of the regression model shown in Table 5 demonstrate that all nine hypotheses derived from the research framework were supported (at the $\alpha=.01$ level) with the exception of $H_{3}$ (Content), $H_{4}$ (Ease of Use), and $H_{8}$ (Promotion). 


\section{Content and Ease of Use}

The fact that the Content and Ease of Use constructs did not emerge as significant predictors of Usability in the multiple regression model was surprising. However, subjective comments from the study participants, as well as a careful consideration of the research progression on Usability, provide a possible answer: Well-designed Web site content and perceived ease of use are expected in Web sites in the current electronic commerce arena. Content and Ease of Use have been listed as contributing to usability as far back as 1997 (e.g., Keeker), and designers of Web sites have paid attention. At this point, more than 15 years later, it appears that content and ease of use have reached a critical mass... to participate in the electronic commerce market, Web sites must have high levels of both. It should be noted that the average scores for these two constructs were 5.28 (Content) and 5.58 (Ease of Use), both out of a maximum of 7. These averages were the second and third highest of the nine constructs. So the Web sites reviewed all received high scores for both Content and Ease of Use, but these constructs were not serving to differentiate usability scores.

\section{Promotion}

The other construct which did not emerge as a significant predictor of Usability in the multiple regression model was Promotion. While disappointing, a careful examination of the two survey questions which make up this construct provide a very plausible explanation. These questions are:

\#21: "I feel this Web site provided a good promotion for the products/services of the company."

\#22: "I feel this Web site I am browsing is promoted well externally on other Web sites and/or other media."

When establishing Usability, it is quite possible that the promotion level of the Web site is not important, and that is in fact what the regression results are indicating. If Usability is "The extent to which a product or a service can be used by specified users to achieve specified goals with effectiveness, efficiency, and satisfaction in a specified context of use" (ISO 9241 definition of usability), then whether that site promotes itself or not is inconsequential. Subjective comments from survey participants support these ideas.

\section{Supported Constructs}

Hypotheses $H_{1} H_{2}, H_{5}, H_{6}, H_{7}$ and $H_{8}$ were all supported. Thus, the constructs Identity, Download Delay, Trust Assurance, Made-for-the-medium, Responsiveness and Emotion are all useful in creating a usable Web site. Business managers and Web site designers would be wise to pay careful attention to these constructs, as they clearly can be differentiating factors in Web site usability which can translate into both traffic and customers.

Finally, we inserted a 1-0 matrix where each Web site was a new column, and 1's were placed in the column for responses concerning that site, and 0's elsewhere. We then re-ran the multiple regression model to gain an overall usability ranking for our $14 \mathrm{Web}$ sites. Note that one Web 
site needed to be left out so it could be the "anchor" point for the ratings. Table 6 shows the similar results leaving out Wal-Mart first and FDS second (both random choices). These two runs are both included simply to indicate that it would not matter which site was removed. Standardized rankings were then created from the Beta coefficients, which lead to the ordinal rankings in the far right column.

Table 6. Usability Ranking of Sites.

\begin{tabular}{l|c|cc|ccc}
\multicolumn{1}{c|}{ Company } & $\begin{array}{c}\text { Beta } \\
\text { with } \\
\text { Wal- } \\
\text { Mart } \\
\text { Removed } \\
0.132\end{array}$ & Difference & $\begin{array}{c}\text { Beta } \\
\text { with } \\
\text { FDS } \\
\text { Komoved }\end{array}$ & & & \\
Standardized & & $\begin{array}{c}\text { Ordinal } \\
\text { Usability } \\
\text { Ranking }\end{array}$ & $\begin{array}{c}\text { Usability } \\
\text { Ranking }\end{array}$ \\
Target & 0.12 & 0.012 & 0.29 & 0.012 & 0.989 & $\mathbf{1}$ \\
Wal-Mart & 0 & 0.12 & 0.17 & 0.12 & 0.867 & $\mathbf{2}$ \\
Sears & -0.004 & 0.004 & 0.166 & 0.004 & 0.863 & $\mathbf{3}$ \\
Bonton & -0.02 & 0.016 & 0.151 & 0.015 & 0.848 & $\mathbf{5}$ \\
Nordstrom & -0.14 & 0.12 & 0.031 & 0.12 & 0.728 & $\mathbf{6}$ \\
Saks & -0.145 & 0.005 & 0.026 & 0.005 & 0.723 & $\mathbf{7}$ \\
FDS & -0.17 & 0.025 & 0 & 0.026 & 0.697 & $\mathbf{8}$ \\
Dillards & -0.226 & 0.056 & -0.056 & 0.056 & 0.641 & $\mathbf{9}$ \\
Dollar_General & -0.228 & 0.002 & -0.057 & 0.001 & 0.64 & $\mathbf{1 0}$ \\
JCPenny & -0.232 & 0.004 & -0.062 & 0.005 & 0.635 & $\mathbf{1 1}$ \\
Belk & -0.297 & 0.065 & -0.127 & 0.065 & 0.57 & $\mathbf{1 2}$ \\
Retail_Ventures & -0.437 & 0.14 & -0.267 & 0.14 & 0.43 & $\mathbf{1 3}$ \\
Family_Dollar & -0.867 & 0.43 & -0.697 & 0.43 & 0 & $\mathbf{1 4}$
\end{tabular}

Kohl's, Target, and Wal-Mart received the highest usability rankings. Given the traffic on those sites, and the market share of those companies, clearly usability of a Web site is an important metric.

\section{CONTRIBUTIONS}

This study examined the measurement of electronic commerce web site usability using established frameworks (MUG) along with additional suggested measures from the literature. Results show that web designers and business managers would be well-advised to recognize that, in 2014 and beyond, Content and Ease-of-Use are expected features of web sites. While very important for a user's usability experience, these factors will not differentiate a company's web site from others. When seeking factors which differentiate sites in today's market, the factors Identity, Download Delay, Trust, Made-for-the-Medium, Responsiveness and Emotion are the ones which merit special attention. Such attention could make the difference for a web site in the increasingly competitive world of electronic commerce. And finally, while these findings are useful, further validation is desirable. In particular, the sample studied was solely business students, and future research should include a more diverse sample. 


\section{REFERENCES}

Agarwal, R. \& Venkatesh, V. (2002). Assessing a firm's web presence: a heuristic evaluation procedure for the measurement of usability. Information Systems Research, 13(2), 168186.

Downing, C. \& Liu, C. (2009). Does Web Site Usability Correlate with Web Site Usage? Journal of International Technology and Information Management, 18(3/4), 443-454.

Eighmey, J. \& McCord, L. (1998). Adding value in the information age: uses and gratifications of sites on the World Wide Web. Journal of Business Research, 41(3) 187-194.

eMarketer.com. (2013). B2C Ecommerce Climbs Worldwide, as Emerging Markets Drive Sales Higher, $\quad$ http://www.emarketer.com/Article/B2C-Ecommerce-Climbs-WorldwideEmerging-Markets-Drive-Sales-Higher/1010004\#iHJm7RbJrdqLgTXr.99, June 27, 2013.

Everard, A., \& Galletta, D. F. (2006). How presentation flaws affect perceived site quality, trust, and intention to purchase from an online store. Journal of Management Information Systems, 22(3), 56-95.

Hair, J. F., Black, B., Babin, B., \& Anderson, R. E. (2005). Multivariate Data Analysis (6th Ed.). Upper Saddle River, NJ: Prentice-Hall.

International Telecommunications Unions (ITU). (2013). Key ICT indicators for developed and developing countries and the world (totals and penetration rates)", Geneva, 27 February 2013.

Keeker, K. (2008). Improving Web Site Usability and Appeal. http://msdn.microsoft.com/enus/library/office/cc889361(v=office.11).aspx, last accessed on February 18, 2014.

Massey, A. P., Khatri, V., \& Montoya-Weiss, M. M. (2007). Usability of online services: the role of technology readiness and context. Decision Sciences, 38(2), 277-308.

Moustakis, V., Tsironis, L., \& Litos, C. (2006). A model of web site quality assessment. Quality Management Journal, 13(2), pp. 22-37.

Nielsen, J. (2000). Desiging Web Usability. New Riders Publisher, Indianapolis, IN.

Palmer, J.W. (2002). Web site usability, design, and performance metrics. Information Systems Research, 13(2), 151-167.

Palmer, J. W. and Griffith, D. (1998). An emerging web site design model for marketing. Communications of the ACM, 41(3), 44-51. 
Venkatesh, V. \& Agarwal, B. (2006). Turning visitors into customers: a usability-centric perspective on purchase behavior in electronic channels. Management Science, 52(3), pp. 367-382.

Venkatesh, V., Morris, M. G., Davis, G. B., \& Davis, F. D. (2003). User acceptance of information technology: Toward a unified view. MIS Quarterly, 26(3), 425-478.

Venkatesh, V. \& Ramesh, V. (2006). Web and wireless site usability: understanding differences and modeling use. MIS Quarterly, 30(1), 181-205.

\section{APPENDIX}

\section{SURVEY INSTRUMENT}

Web Site Usability Survey

Please type the site address you have just visited:

In 150 words or less, describe the appearance of the site and your experience of the site visit:

Please rate the following by checking the number that best reflects your opinion of the Web site you just visited:

1 - Strongly Disagree

2 - Disagree

3 - Slightly Disagree

4 - Neither Agree or Disagree

5 - Slightly Agree

6 - Agree

7 - Strongly Agree

(1). I feel this Web site clearly stated its purpose for using the site.

(2). I feel this Web site could distinguish itself compared to other retail Web sites I visited before.

(3). The speed in which the Web site provided information on the screen was fast enough.

(4). The rate at which the information was displayed was fast enough.

(5). I feel this Web site provided information relevant to the customer.

(6). I feel this Web site offered personalized information and layout. 
(7). I feel this Web site provided timely information.

(8). I feel the amount of information displayed on the Web site was adequate.

(9). I find it easy to get this Web site to do what I want it to do.

(10). The sequencing and navigation on this Web site were clear.

(11). The layout of pages made tasks easier.

(12). The search functions provided in this Web site helped me find relevant information.

(13). I feel that this Web site made a reasonable effort to protect my personal information.

(14). I feel the Seals Program (such as Truste and BBBOnline) in this Web site helped ensure that my personal information would be protected.

(15). I feel this Web site's privacy policy made me feel that the Web site is trustworthy.

(16). The Web site security measures made me feel the Web site is trustworthy.

(17). I feel engaged/involved by the interactivity of the site.

(18). The extent to which this Web site can be tailored to fit my specific needs was adequate.

(19). I feel this Web site was responsive to the customers' concerns.

(20). The feedback options and FAQ provided in this Web site were adequate.

(21). I feel this Web site provided a good promotion for the products/services of the company.

(22). I feel this Web site I am browsing is promoted well externally on other Web sites and/or other media.

(23). I feel this Web site provided features to promote customers' excitement.

(24). The visit of this Web site was enjoyable.

(25). After visiting this Web site, I would be willing to provide my personal information to this site.

(26). I would be willing to visit this Web site again.

(27). I would be willing to recommend this Web site to others.

(28). I would be willing to purchase from this Web site if needed. 
(29). I have positive things to say about this Web site.

(30). I feel that this Web site provided me the opportunity to be part of an online group or community.

(31). I feel this Web site provided clear and understandable feedback regarding my progress of the site visiting.

(32). I feel this Web site reflects most current trend(s) and provides nice design for the site visit.

(33). Gender:

Male Female

(34). To what age group do you belong?

17-20 21-25 26-30 31-35 36-40 41-45 46-50 Over 50

(35). What statement best describe your level of experience of using Web?

I have used the Web a few times before this survey

I use the Web a few time a month

I use the Web every week

I use the Web almost every day

Your Name:

Zid:

Thank you for taking this survey! Please Click the Submit Button. 